\title{
La imagen vestida El estampado textil vestimentario como hecho visual de interés disciplinar*
}

\section{Lic. María Candela Caudana, Fadu/unl}

* Reseña de la tesina de graduación de la Licenciatura en Diseño de la Comunicación Visual. Selección de la Dirección de la Carrera.
El objeto de estudio de nuestra tesina fue el estampado textil diseñado para indumentaria. El mismo constituye un tipo particular de manifestación de la imagen visual que, en principio, se inscribe en el campo de acción de una disciplina proyectual distinta del Diseño de Comunicación Visual: el Diseño Textil.

Sin embargo, los supuestos de los que partimos, que determinaron la elección del tema y dieron forma a la hipótesis de trabajo, tenían que ver con que el estampado textil sería, para el Diseño de Comunicación Visual, un objeto de mayor interés que el que hasta ahora se le ha concedido y de mayor incumbencia que la que hasta ahora se le ha reconocido. La caracterización de tal interés y pertinencia fue, en definitiva, el objetivo general que estructuró el desarrollo de la investigación.

Para la realización del estudio, construimos un corpus analítico de treinta piezas de diseño textil (imagen 3). Entendimos que el mismo debía ser representativo de la producción textil actual, a escala internacional, y cuya calidad, en términos proyectuales, estuviera legitimada por alguna instancia institucional -que en nuestro caso fue la necesaria mención de su autor en alguna de las dos publicaciones especializadas seleccionadas (Hidalgo, 2009 y Quinn, 2009).

El trabajo de análisis tuvo dos instancias metodológicamente diferenciadas. La primera consistió en un fichaje sistemático, descriptivo y analítico, de cada una de las piezas del corpus, comprendiendo las siguientes macro categorías: características generales de la estampa (basado, el análisis, en conceptos de Saltzman, 2007 y Meller y Elffer, 2002); características tecnológicas; morfológicas (Dondis, 2000 y Wong, 1982) y retóricas (Groupe $\mu$, 1993).

Cabe destacar que ya en esta etapa preliminar comenzamos a observar cómo nuestro (atípico) objeto de estudio suscitaba la necesidad de modificar o matizar las formulaciones y categorías analíticas existentes sobre la imagen visual para adecuarlas a la descripción de sus peculiaridades. Por ejemplo, tuvimos que generar una clasificación que permitiera describir la particular relación morfológica que se establece entre la imagen y la topografía del cuerpo; por otro lado, en el análisis retórico, encontramos que era necesario matizar algunos conceptos del Grupo $\mu$ (op. cit.) atendiendo a las operaciones que íbamos encontrando al completar las fichas. Entendemos que este tipo de intervención metodológica y teórica constituye uno de los aportes relevantes que realiza nuestra tesina, además de los derivados de los objetivos específicos planteados.

Luego del fichaje, en la segunda parte de la investigación, recurrimos a estrategias cualitativas de tipo interpretacional a partir del estudio bibliográfico (Entwistle, 2002; Saltzman, 2007; Calvera, 2005 y 2007; Cerezo, 2004; Martín Juez, 2004 y 2007) y su contrastación con los casos analizados, fundamentalmente para enriquecer la reflexión sobre nuestro objeto desde los puntos de vista sociológico, comunicacional y estético.

En esta instancia pudimos pensar y aportar ideas relativas a varios aspectos que son actualmente objeto de debate disciplinar y, en gran medida, polémicos: el lugar de la moda (como tendencia) en el diseño; la supuesta femineidad de todo lo que atañe a las prácticas del vestir y que ha determinado su relativa desatención por parte de los estudios sociales; el valor de lo estético -en general poco reconocido- en el proyecto de diseño, entre otras cuestiones. Constantemente trazando vínculos y señalando diferencias entre las distintas disciplinas proyectuales que poníamos en consideración (no sólo el Diseño de Comunicación Visual y el Diseño Textil, sino también el Diseño Industrial, de la mano del aporte de muchos de los autores compilados en los textos de Calvera -2005 y 2007-). Las conclusiones del trabajo fueron numerosas, en la medida en que debieron dar cuenta de cada una de las categorías y subcategorías conceptuales del Marco Teórico que hicimos intervenir en el análisis, en pos de aqueIla caracterización propuesta como objetivo general. El trabajo que realizamos fue, desde este punto de vista y conscientemente, extensivo: siendo un espacio de va- 

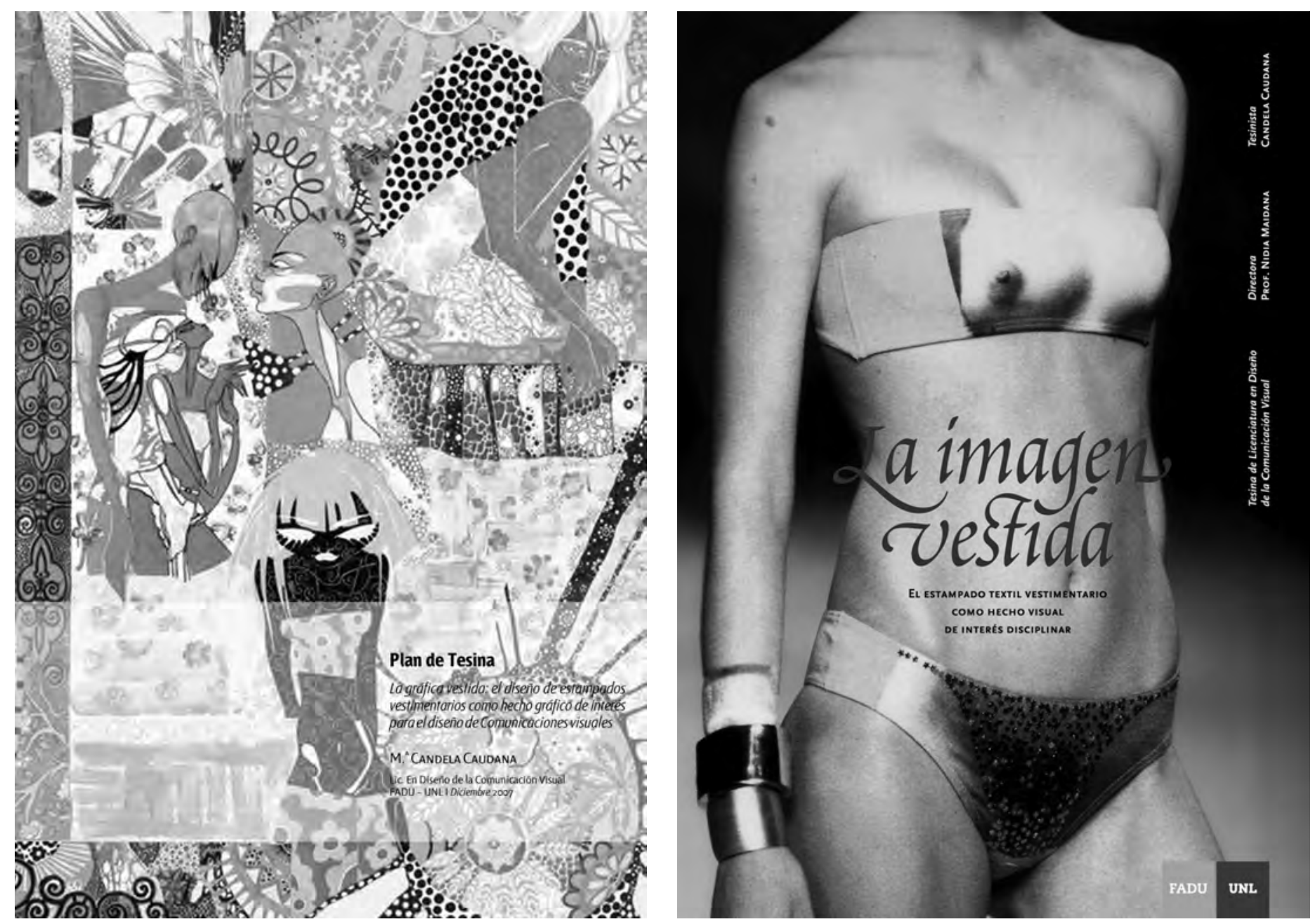

Imágenes 1 y 2: Las tapas correspondientes al Plan de Tesina y a la presentación final del trabajo ilustran, con una claridad que no percibimos hasta la finalización el proceso, las dos grandes cuestiones que sostenían el supuesto inicial, la del interés y la especificidad del estampado textil vestimentario: por un lado, una riqueza visual basada en la exhuberancia, la complejidad y la diversidad formal que suelen presentar estas piezas y, por el otro, la particular carga semántica que el cuerpo portante agrega a este tipo de imágenes, un conjunto diverso de significados relacionados con la sexualidad y el erotismo, la identidad individual y la pertenencia social, entre otros. La realización de la investigación permitió precisar y profundizar conceptualmente esos supuestos iniciales. Las imágenes de tapa fueron, respectivamente, una ilustración de moda de Sonya Suariyan y una fotografía de pasarela de un diseño de la brasileña Rosa Cha. 
Imagen 3. Composición del corpus analítico organizado por autor, nacionalidad, fecha de realización y publicación especializada en la que el diseñador es mencionado.

Imagen 4. Exploración de la relación imagenvolumen. Paula Castro. Exhibición Situations in the woods, Milán, 2008. Imagen 5. Exploración de la relación imagen-cuerpo. Martín Churba, Tramando. En Saltzman (2007:55).

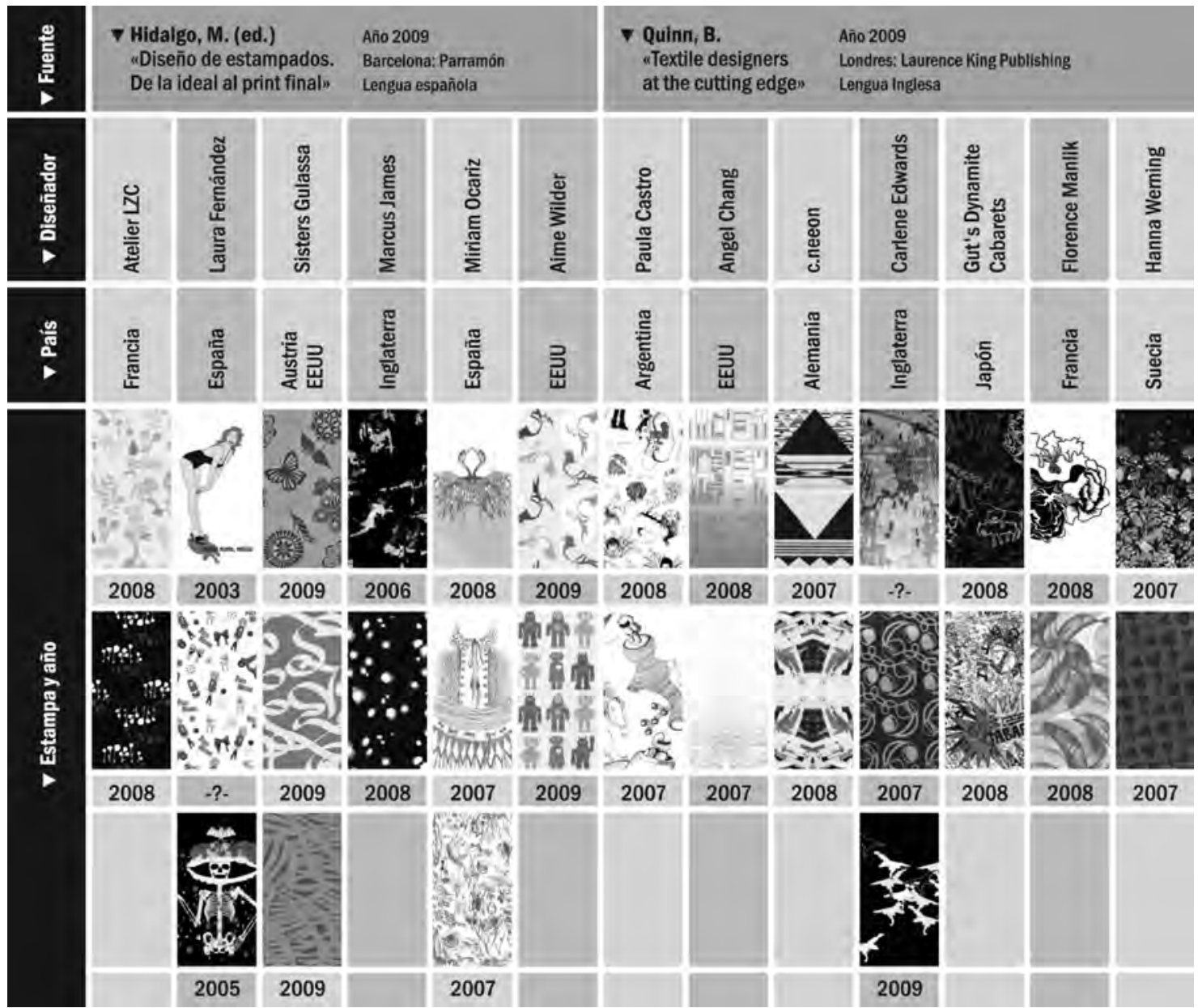
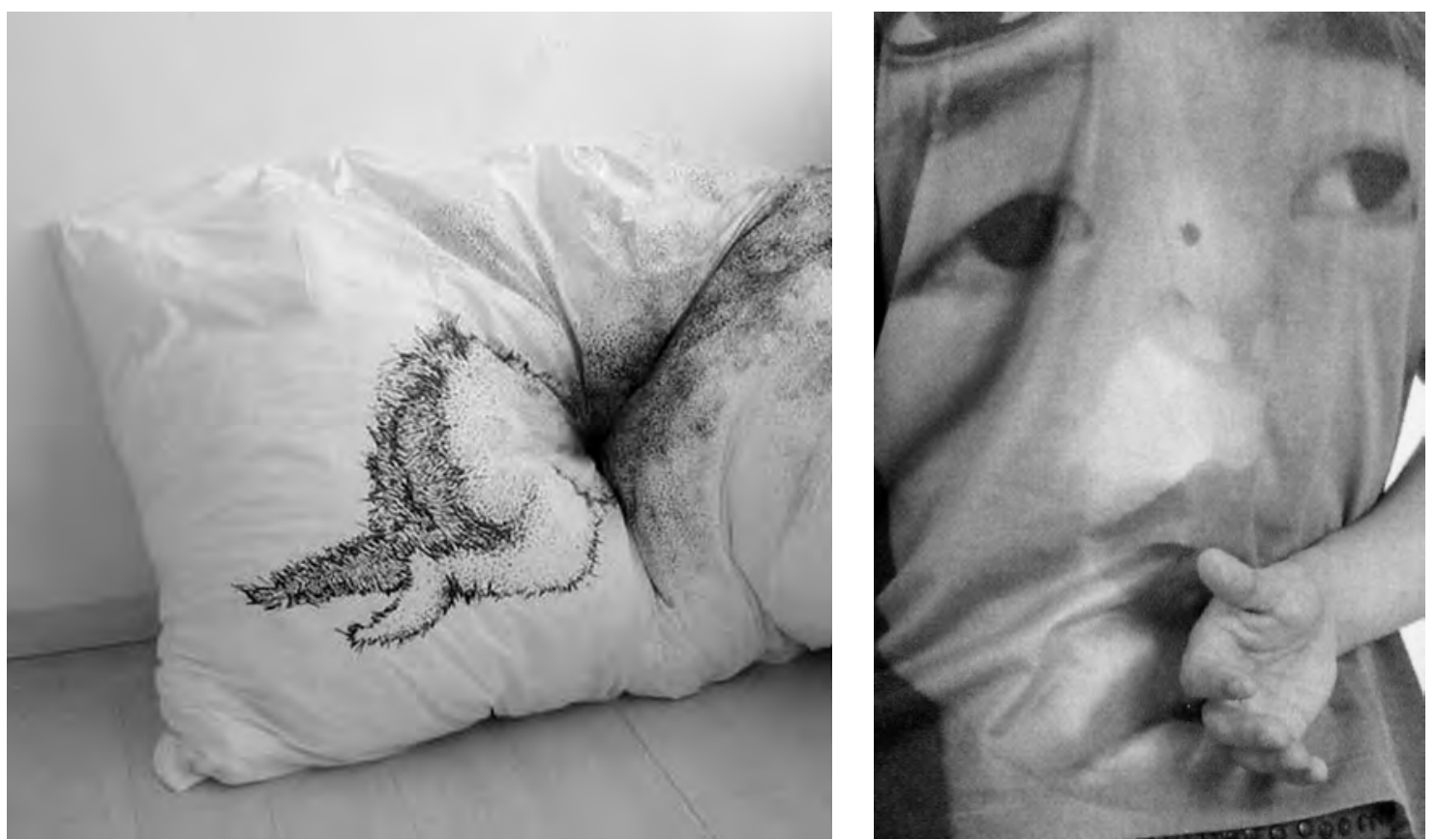
cancia teórica, nos pareció necesario tratar de cubrir la mayor cantidad de aspectos posibles, dejando para desarrollos posteriores la profundización de los mismos. A modo de síntesis de nuestros resultados, diremos, en primer lugar, que pudimos encontrar regularidades formales y retóricas que permiten proponer la existencia de una suerte de lenguaje específico de la estampa textil vestimentaria.

En relación con esto, entendemos que la alianza (formal y conceptual) con el cuerpo portante es uno de los factores específicos y más interesantes del estampado y merece ser considerado desde el análisis y desde el diseño de este tipo de imágenes. Si bien en las piezas que constituyeron nuestro corpus no encontramos un aprovechamiento significativo de esa facultad, durante el desarrollo de la investigación tuvimos la posibilidad de ver otros casos en los que eso sí ocurría (imágenes 4 y 5). Los sistemas de impresión que dominan la producción industrial dificultan el aprovechamiento de esa relación, pero la incipiente impresión digital promete generar un cambio al respecto, de la mano del llamado diseño a medida.

Desde el punto de vista comunicacional, la estampa, tomada en su doble función de constructora de sentido y de lugar de plasmación de los sentidos construidos socialmente, es una imagen muy reveladora de su cultura $y$, por eso mismo, un objeto muy interesante para los estudios sociales, los estudios sobre la imagen y los trabajos proyectuales.

Desde el punto de vista estético, en la estampa textil, y en general, en la indumentaria, se pone en evidencia la necesidad propiamente humana de gratificación simbólica y sensorial que el diseño ha desempeñado durante toda su historia, pero que ha sido y sigue siendo un valor discutido (o, como mínimo, poco reconocido) desde la teoría y la enseñanza.

Tal como dijimos, creemos que una aportación destacable de nuestro trabajo radica en la apertura de futuras líneas de investigación sobre el tema. Queremos finalizar esta reseña destacando las siguientes, que son las que más nos interesan: a. la posibilidad de enriquecer la investigación mediante la incorporación del trabajo empírico, estudiando el objeto en su campo de acción cotidiano y entrevistando a sus creadores y b. la realización de tesinas (u otros desarrollos) proyectuales que lleven al terreno de la praxis los aportes conceptuales de esta investigación.

\section{Bibliografía}

Calvera, A. (comp.) (2004): Arte ¿? Diseño. Nuevos capítulos de una polémica que viene de lejos. Barcelona: G. Gilli, 2005.

Calvera, A. (comp.) (2007): De lo bello de las cosas. Materiales para una estética del diseño. Barcelona: G. Gilli.

Cerezo, J. (2004): «Con el arte a otra parte o cómo acabar de una vez por todas con la cultura del diseño». En: Calvera, A.: Arte ¿? Diseño. Nuevos capítulos de una polémica que viene de lejos. Barcelona: G. Gilli, 2005.

Dondis, D. (1973): La sintaxis de la imagen. Introducción al alfabeto visual. Barcelona: G. Gilli, 2000.

Entwistle, J. (200o): El cuerpo y la moda. Una visión sociológica. Buenos Aires: Paidós, 2002.

Groupe $\mu$ (1992): Tratado del signo visual. Para una retórica de la imagen. Madrid: Cátedra, 1993.

Hidalgo, M. (ed.) (2009): Diseño de estampados. De la ideal al print final. Barcelona: Parramón.

Quinn, B. (2009): Textile Designers at the Cutting Edge. Londres: Laurence King Publishing.

Martín Juez, F. (2004): «Ordinario y extraordinario». En: Calvera, A. Arte ¿? Diseño. Nuevos capítulos de una polémica que viene de lejos. Barcelona: G. Gilli, 2005.

Martín Juez, F. (2007): «Flor y canto. Filósofos y pensadores anónimos del México prehispánico».

En: Calvera, A. (comp.) (2007): De lo bello de las cosas. Materiales para una estética del diseño. Barcelona: G. Gilli.

Meller, S.; Elffer, J. (1991): Textile Designs: Two Hundred Years of European and American Patterns Organized by Motif, Style, Color, Layout, and Period. Nueva York: Paperback, 2002.

Saltzman, A. (2004): El cuerpo diseñado. Sobre la forma en el proyecto de la vestimenta. Buenos Aires: Paidós, 2007.

Wong, W. (1979): Fundamentos del diseño bi- y tri-dimensional. Barcelona: G. Gilli, 1982. 